\title{
الخدمة الاجتماعية والممارسة المهنية والبيئة في مجتمع \\ متغير - بحث تحليلي اصطلاحي - مفاهيمي - تنظيري
}

أ.م. د. عبدالحميد علي سعيد/ جامعة صلاح الدين/ اربيل

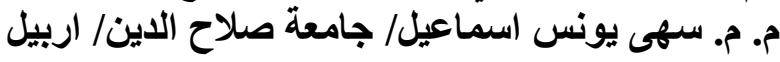

تعد ازمة الانسان مع بيئته من الازمات التي تحتاج الي دراسـة والاهتمـام ، لاسيما بعد اختلالات البيئة

الطبيعية، اي عندما بدأت عناصر البيئة تعاني من تدخلات الانسـان التعسفية والاستخدام غير المنضبط ، ولهذا تظافرت الجهود للحد من هذه الازمة واصبحت قضية حماية البيئة لها حضور اً اساسياً في العديد من المؤتمرات العالمية، اذ يعد انعقاد مؤتمر "استوكهولم" للتنمية البشرية في عام 1972 يشكل البداية الفعلية لـ "عولمة التفكير البيئي " وبداية الوعي الجماعي بحتمية حماية البيئة وصيانتها ـ فضلا عن ذلك بدأت " الاسرة الدولية البيئية " تبحث في ريو 1992، عن حلول جذرية للمشاكل البيئية وتم ربط البيئة بالتنميـة المستدامة وفي عام 2002 لم يكن امام المجتمع الدولي الى اعادة التفكير الجدي في قضايا البيئة ـ لكن عام 2012 شكل المحطة الفاصلة في قضايا حماية البيئة فاصبح العالم مطالبا في ريو ببذل الجهود ليس لتشخيص البعد البيئي فقط بل لتقديم الجهود البيئة و التفكير في اليات فاعلة لحماية البيئة في المستقبل وتدارك اخطاء الماضي. كما عد الاهتمام بالبيئة وتتميـة الوعي البيئسي من ابرز اهتمامـات مهنـة الخدمـة الاجتماعيـة في الوقت الحسالي التي ركزت على ايجـاد علاقـة ايجابية متوازنة بين الانسان في مختلف صوره والبيئة التي يعيش فيها للحفاظ على هذه العلاقة من خـلال ايجاد ستر اتيجية ذات خطط نظرية و عملية تجعل من مهنة الخدمة الاجتماعية وممارسيها لهم الدور الاكبر في تنظيم

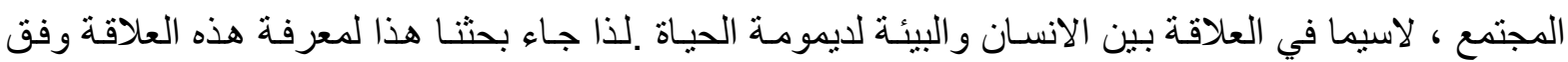
المحساور الآتيـة : (اولا : عناصر البحث ( مشـكلة واهميـة وأهداف البحثـ ثانيـا : الخدمـة الاجتماعيـة والممارسـة المهنيـة والبيئة " قراعة اصطلاحية ومفاهيميـة " ـ ثالثا: الخدمـة الاجتماعيـة والممارسـة المهنيـة والبيئة " قراعة تنظيرية وفكرية "- الخاتمة)

اولا : عناصر البحث ( مشكلة واهمية واهداف البحث ). مشكلة البحث: تعد مشكلات البيئة اليوم من اهم معوقات البناء و النمو والتي لو استمرت فسوف تعوق تحسين حياة الافر اد و الجماعات و المجتمعات، لذلك فانه يمكن للخدمة الاجتماعية ان تقوم بدور ها في هذا الصدد من خلال اسهامها الفعال و المباشر في العمل على تعديل السلوك الانساني و السلبي اتجاه البيئة والحد من التلوث و المعاونة في انماء الوعي البيئي ـ ومما يؤكد على اهميـة التفاعل بين مهنـة الخدمة الاجتماعيـة والبيئة من ان مهنة الخدمة الاجتماعية هي الوسيط بين الانسان والبيئة والتي يعيش فيها وانها تعمل على تسهيل العلاقة بين الفرد و البيئة و اهمية قيام الانسان بدور ايجابي تجاه المشكلات التي تؤثر عليه في اطلار البيئة التي يعيش فيها و هي بذللك تأخذ مفهوم الاجتماعي للتعامل مع المشكلات الخاصة بالمجتمع ومنها مشكلة البيئة . ان مشكلات البيئة اصبحت الثــل الثــاغل للبشـرية الان اذ ليس هنـالك دولـة او مجتمع خـارج حدود خطورة قضية البيئة ، وما استدعى اهتمامي لموضوع البيئة هو تللك الاخطار المحدقة بالبيئة بسبب مـا اصـابها من اضر ار الحروب فقد شملت هذه الاضرار التربـة والنباتات ومصـادر توفير ميـاه الصـالحة للشـرب ووسـائل 
الصـرف الصـحي والجو وحتى الانسـان فانـه تعرض الـي الامـر اض متعددة نتيجـة هذه الاضـرار التي لحقت

بالبيئة، فضلا عما تقدم ان مشكلات البيئة تحتاج الى اناس متخصصين للحد منها في كل المجالات لاسيما في المجتمعات المتغيرة ، التي تعرضت الى مآسي وحروب و انتكاسات ، ثم الى استقرار وتوازن بعد التخلص من

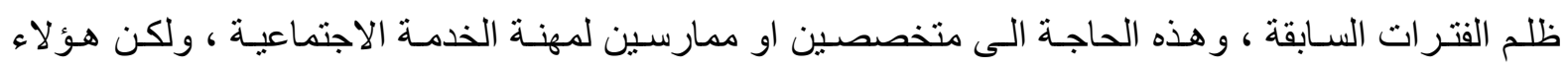

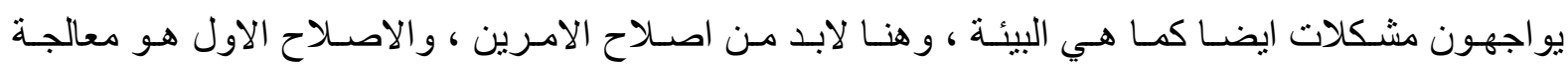
المشكلات او المعوقات التي يحتاجها الممارسين لكي ينهضوا بخططهم في حل مشكلات البيئة من خلال عملهم ودر استهم، ومن اجل هذا قمنا ببحثنا هذا .

الهية البحث: ان الدراسات البيئية من بين الموضوعات التي نالت اهتمـام الباحثين في الآونـة الاخيرة

في شتى التخصصات و انو اعها ، وتكمن ايضا في الازمة الحقيقة التي تعيثـها المجتمعات المتغيرة اليوم نتيجة التلوث التي ملاحظتها بالعين المجردة ، كما تكمن اهمية هذه البحث في زيادة المعلومـات و المعرفة العلميـة في مجال الممارسة المهنية للخدمة الاجتماعية وايضا في مجال حماية البيئة وذلك عن طريق الدراسات و الاتجاهات والتجارب السابقة. ويعد الاهتمام بالبيئة وتتمية الوعي البيئي من ابرز اهتمامـات مهنـة الخدمة الاجتماعيـة في

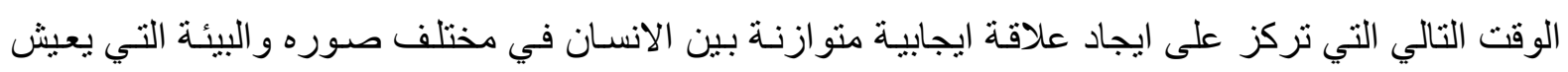
فيها، وان مشكلات البيئة اليوم تعد من اهم معوقات البناء والنمو والتي لو استمرت فسوف تعوق تحسين حياة الافر اد و الجماعات والمجتمعات ، واهمية البحث هنا تكمن ليس في الحد من مشكلات البيئة، انما تأتي من اهمية

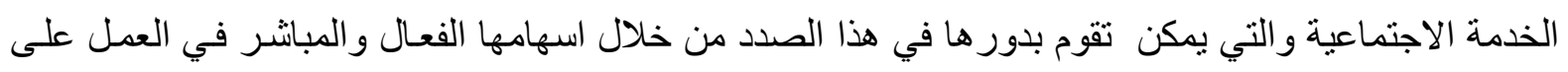
تعديل السلوك الانساني و السلبي اتجاه البيئة والحد من التلوث و المعاونة في انماء الوعي البيئي. فضلا عن ذلك،

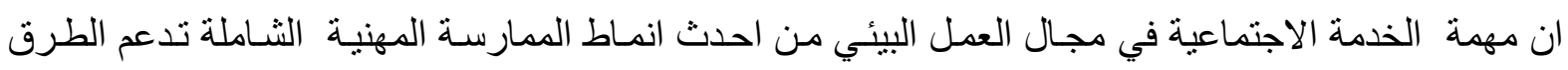
الاخرى في حمايـة البيئة ، فليس بينهـا تعـارض او تتـافر حيث انها تسـى في مجمو عها الى تحقيق الهدف المشترك بينهم و هو مساعدة الانسان في ان يعيش حياة افضل في ضوء قدر اته وامكانياته المتاحة .

أهداف البحث : يهدف بحثنا الآتي التعرف على ما يأتي : التعرف على مفاهيم الخدمة الاجتماعية و الممارسة المهنية والبيئة.

التعـرف علـى الاتجاهـات والمـدارس الفكريـة والتنظيريـة المتعلقـة بالخدمــة الاجتماعيـة و الممارســة المهنيـة و علاقتهما بالبيئة وكيفية توظيفهما.

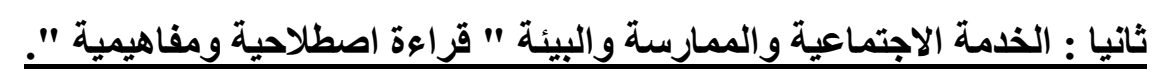

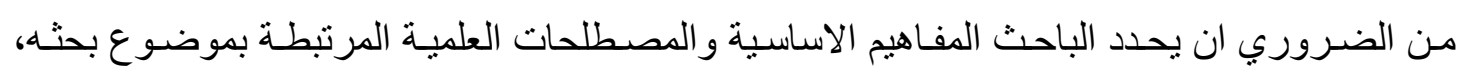
حيث انه كلما اتسم هذا التحديد بالدقة امكن للباحث ان يجري بحثه على اساس علمي سليم.. وفي بحثنا هذا سنتناول المصلحات و المفاهيم العلمية الاتية :

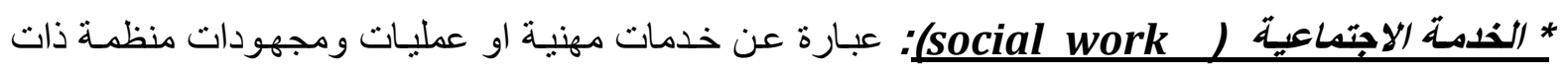
صبغة علاجية ووقائية وانسانية تؤدي الى الناس وتهدف الى مساعدتهم كأفراد او جماعات في الوصـول الى 
الحياة كريمة تسودها علاقات طيبة ومستويات اجتماعية تتمشى مع رغباتهم و امكانياتهم وتتفق مع مستويات و اماني المجتمع الذي يعيشون فيه ، وتؤدي الخدمة الاجتماعية وظيفتها عن طريق تقديم خدمات ماديـة ومعنويـة الى من يحتاجها من الافر اد و الجماعات و المجتمعات في مؤسسات او هيئات بو اسطة اشخاص مهنيين ومعدين

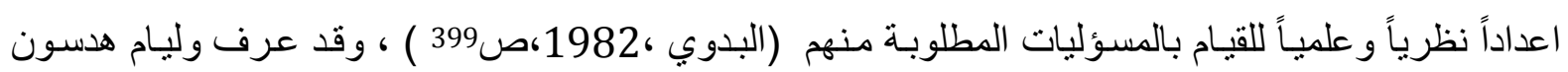
1925 : بانها نوع من الخدمة التي تعمل من جانب على مساعدة الفرد او جماعـة الاسرة التي تعاني مشكلات لتتمكن من الوصول الى مرحلة سوية ملائمة وتعمل على جانب اخر على ان تزيل بقدر الامكان العوائق التي

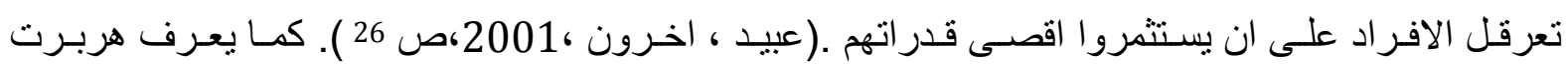
ستووب 1948 : فن نوصيل الموارد المختلفة الى الافراد و الجماعـة والمجتمع لاشباع احتباجـاتهم عن طريق

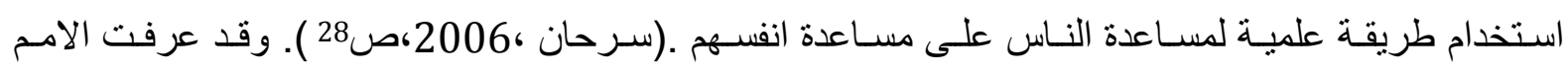
المتحـدة الخدمـة الاجنماعيـة عـام 1960: و وهي تحقيـق التكيف و التفاعل المتبـادل بـين الافر اد وبيئاتهم الاجتماعية وتسعى في تحقيق هذا بمجموعة من البر امج و الانشطة المنظمـة .امـا الجمعيـة القومية للأخصـائيين الاجتماعين 1970 فانها تعرف الخدمـة الاجتماعيـة بانها عبـارة عن نشـاط مهني لمسـاعدة الافر اد و الجماعـات و المجتمعات لتحسين قدر اتهم او استعادتها للاداء الاجتمـاعي وايجاد ظروف اجتماعيـة مواتيـة لتحقيق اهدافهم

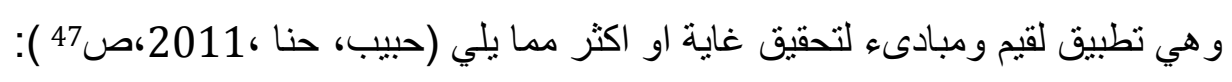

$$
\text { 2. }
$$

3. مساعدة المجتمعات او الجماعات بمدهم بالخدمات الاجتماعية والصحية وتحسين القائم منها . .

$$
\text { 4. المساهمة في العملية التشريعية. }
$$

نشـتق من التعـاريف السـابقة التعريف الآتي: هـي مهنـة وطريقة علميـة تسـاعد الفرد على مواجهة مشكلاته وتتميـة قدر اتـه للوصـول الى مسنتوى من الحيـاة تتفق مسع رغباتـه ، وكذلك تسـاعد النظم الاجتماعيـة

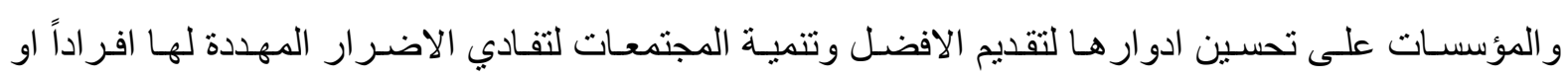
مجتمعات وذللك باستثمار الطاقات الثخصية البيئية . مهونية *مفهوم المعارسة (Practice) : هي التطبيق العملي للافتر اضات النظرية ، وهي طريقة امتحان صحة او

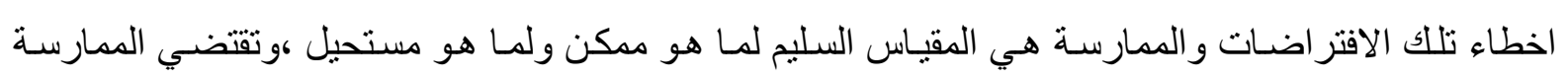

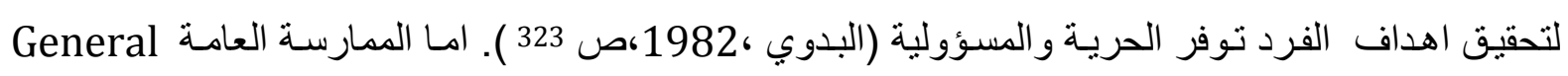
كمـا عرفها قاموس الخدمـة الاجتماعيـة : " انها تلك الممارسـة التي تقوم على اسـاس عـام من

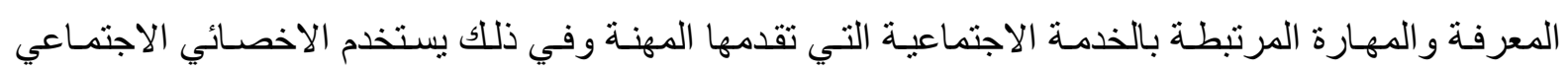

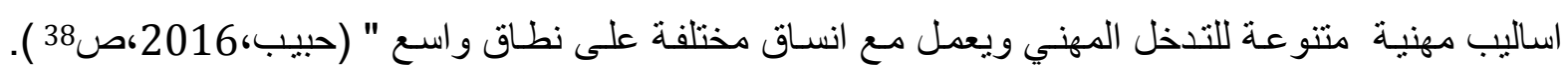
و وتتطلـب الممارسـة العامـة للخدمـة الاجتماعيـة المعرفـة بالسـلوك و التطــور الانسـاني لمو اقـف الاجتماعبـة و الاقتصادية والثقافية وتتفاعل كل هذا العو امل معاً (السروجي ،2009،ص209 ) ـكما عرفت الممارسـة العامـة للخدمة الاجتماعية :بانها التطبيق المهني لقيم والمبادىء الخدمة الاجتماعية لتحقيق احد الاهداف الاتيـة : " تقديم 
الخدمات الضـرورية للافر اد ، تزويــ الافر اد بالارشـاد والعـلاج النفسي بالاضـافة الـى الاسـر والمجتمعـات ،

وتحقيق الخدمات الصـحية و الاجتماعيـة المقدمـة للجماعـات و المجتمعات ،و المشــاركة في العمليـات التشـريعية المتعلقة بهم "(السروجي ،2009،ص20) ). ويعرفها "كار لا ميلي وزملائها" : على انها تلك الممارسة التي تقدم مدخلا معاصر لتحقيق الغرض من الخدمة الاجتماعية وتتحرك الممارسـة من بؤرة اهتمامها بـالفرد الى مركز اوسع للتخخل المهني مع انساق متعددة وبمعنى اخر فان الممارسـة العامـة للخدمة الاجتماعيـة تركز على تفاعل

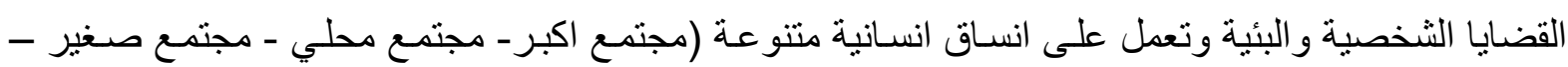
منظمات معقدة - مؤسسات - جماعات رسمية - جماعات غير رسمية - افر اد ) لاحداث التغيرات التي تؤدي

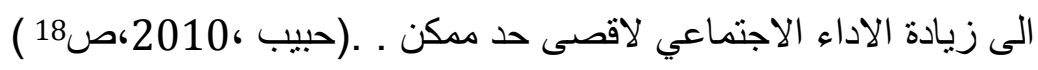

\section{:Professional practice of social service لمعارسة المهنية للخدمة الاجتماعية***}

عرفتها دائرة المعارف الخاصة بالخدمة الاجتماعية سنة 1997بانها مهنـة تطبيقيـة تسعى الى مسـاعدة الانسـان من خـلال الاستفادة من كافة الموارد المتاحسة بـالمجتمع وبو اسطة اخصـائين اجتمـاعين مدربين ولديـه مهار ات منميزة في العمل الاجتماعي ومن خلال ما يقومون به من ابحاث ومشورة مهنية ويسهمون في تمكين افر اد المجتمع من مواجهة مشكلاتهم كما يسهون في تطوير اسـاليب العمل بالمؤسسـات وفي تحقيق الوظـائف الاجتماعية وحماية المجتمع من الامر اض الاجتماعية (عبداللطيف ،2007،ص212) ـ و الممارسة المهنية للخدمة الاجتماعية بذلك هي الادوار المهنية التي تقوم بها الاخصـائيون كتطبيق عملي للمعـارف النظريـة لاختبار مدى النى صحتها باعتبار ها مقياسا واقعيا ومناسبا لصحة المعارف النظرية ، او التوصل الى اخرى جديدة لتحقيق اهداف الممارسة المهنية المحددة سلفاً (السروجي، 2009 ،ص55 ). امـا قاموس الخدمة الاجتماعيـة لعام 2003 فقد عرفها بانها مهنـة تعتمد على قاعدة معرفيـة اسـاس مهاري مـن اجل مسـاعدة افر اد المجتمع على مواجهة المشكلات لكي يتمكنو امن الاستفادة بقدر اتهم و العمل على تمكين الفئات القوية من استثمار قدر اتهم المتبقية لحل

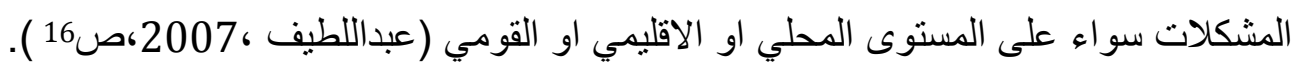

ومما تقدم من التعاريف السـابقة يمكن تعريف الممارسـة المهنيـة للخدمـة الاجتماعيـة : انها عبـارة عن نشاط وخبرة عملية وفنية يقدم من قبل اخصائين في مجالات الخدمة الاجتماعية سواء طبية ، اجتماعية ،او البيئية لمساعدة الافراد او المؤسسات في مواجهة المشكلات وايجاد الحلول المناسبة لها . .

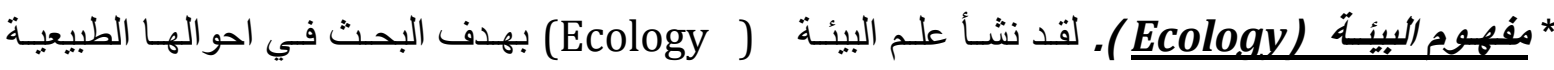
ومجمو عات النباتات او الحيو انات التي تعيش فيها ، و الكائنات الحيـة الموجودة في هذه البيئة وكلمـة ايكولوجي

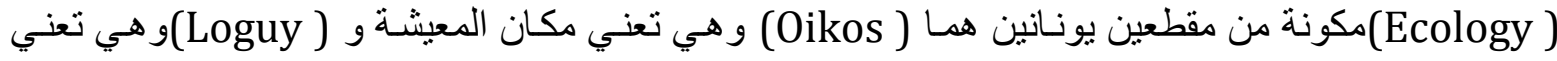
در اسة و على ذلك كلمة الايكلولوجي ( Ecology) علم در اسة اماكن المعيثة للكائنات الحية وكل مـا يحيط بها ولقد روج في اللغة العربية على اطلاق اسم علم البيئة على التسمية (Ecology) فاختلط الامر بذللك مـع مفهوم. البيئة (Environment) و اصبح علم الايكولوجي (Ecology)و علم البيئة (Environment) كانهما تسميتان متر ادفتان لمجـال و عمل واحد ولكن الواقع يختلف عن ذلك تمامـا فعـالم الايكولوجي يعني كما ذكر ((ايوجين ادوم )(بدر اسـة وتركيب ووظيفة الطبييعة ، اي انه بمعنى مـا يحدد الحياة وبكيفية استخدام الكائنات 
للعناصر المتاحة . اما عالم البيئة (Environmentalist) فيعني بدر اسة التفاعل بين الحياة والبيئة ، اي انهـ يتناول تطبيق معلومات في مجالات معرفية مختلفة في دراسة السيطرة على البيئة فهو يعني بوقايـة المجتمعات من التاثير ات الضـارة كمـا يعني بالحفاظ على البيئة محليـا وعالميـا من الانثطة البشرية ذات التاثير الضـار ويتحسن نوعيـة البيئة لتنتاسب حياة الانسـان .(النكلاوي ،واخرون ،2003،ص 14) ـ وتعرف البيئة من قبل مؤتمر الامم المتحدة الذي عقد في استوكهولم 1972 بانها رصد الموارد المتاحة في وقت مـا ومكان مـا ،

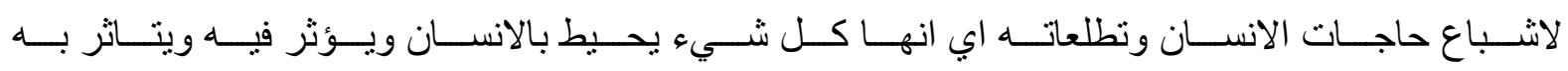
(دويدري،2004،صن323).

كما وتعرف البيئة: هي الوسيط المحبط بالانسـان والذي يشمل كافة الجوانب المادية و الغير الماديـة ، و البشرية منها والغير البشرية فالبيئة تعني كل ما هو خارج عن كيان الانسـان وكل مـا يحيط بـه من موجودات فالهو اء الذي يتتفسه و الانسان والماء الذي نشربه والارض التي يسكن عليها ويزر عها وما يحيط بـه من كائنات حيـة او من جمـاد هي عناصـر البيئة التي يعيش فيها والتي تعتبر الايطسار الذي يمـارس فيسه حياتهـ ونشـاطه . سيدحسن ،2010،ص60) . ومن ناحية اخرى نجد ان البيئة تعرف في مفهومها الواسع على انها تتضمن كل الجو انب الفيزيائية والاجتماعية و الاقتصادية والجمالية التي تؤثر على حياة الافر اد والمجتمعات وبـالاتي تسـاهم في تحديد شـكها النهائي و العلاقـات الموجـودة بها وكذلك فرض استمر اريتها.(سماقه يـي ،2006،ص 14 )

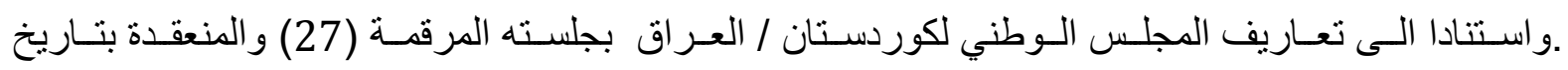
2008/6/11 تشرع القانون الاتي: 2

قانون حماية وتحسين البيئة في اقليم كوردستان - العر اق ومن التعاريف التي يقصد بها المعـي المبينة

از اء اغر اض هذا القانون منها :

البيئة المحيط الحيوي الذي يشمل الكائنات الحية من انسـان وحيوان ونبات و المكونـات الاحياتية وكل

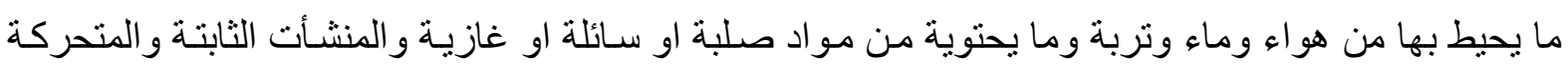
التي يقيمها الانسان .

حماية البيئة و المحافظة عليها ومنع تلوثها وتدهور ها او الحد منهما . .

ومن خلال التعاريف السابقة يمكننا نستمد التعريف الاتي لحماية البيئة : مجمو عة انشطة عملية و علمية تساعد في المحافظة على البيئة و المحاولة لديمومة الموارد البيئية واستغلالها بالثكل الافضل عن طريق تغير : السلوكيات المتبعة في استغلال البيئة .

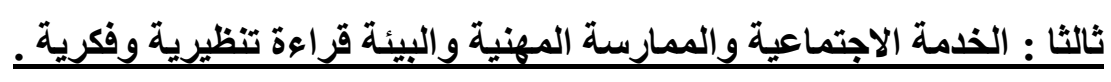

النظريـة في علم الاجتمـاع و الانثروبولوجيـا و الخدمـة الاجتماعيـة تؤدي دور الدليل والموجـه لطالب المعرفة العلمية كما أنها تنطوي على مجموعة من الأفكار المجردة والمتر ابطة تر ابطاً منطقباً والتي يمكن أن

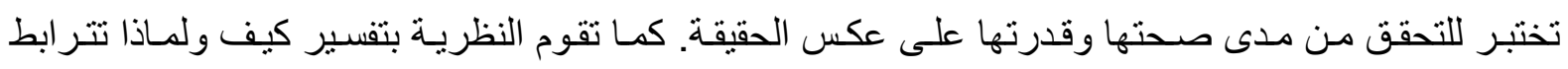
مجمو عة من الحقائق ذات الصلة بموضدوع مـا أو قضية مـا، كذللك تسـاعد في تحليل العلاقة بين مجموعة من 
الأحداث و الوقائع، ذلك لفهمها و التمكن من وضع تعميمات يسهل أمر تداولها والإفـادة منها. لذا يؤكدو يقول الباحث "كـابلان" ليس مـن الضـروري ان يلتزم الباحث بنظريـة واحدة فقط، بـل من الافضـل لـه ان يستطيع

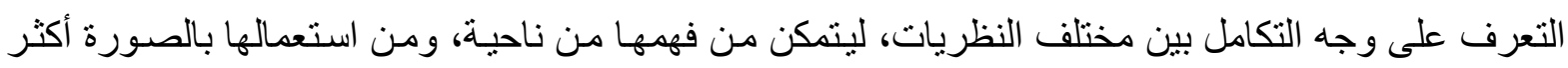

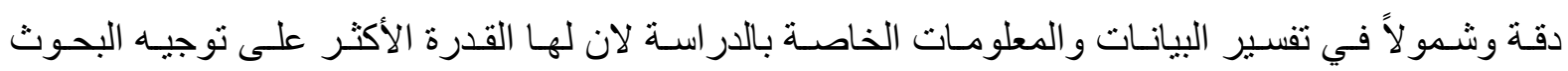

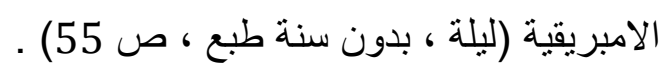

ووفق مـا تقدم نـرى يستطيع البـاحثون ان يتعـاملوا أو يزاوجوا بين أكثر من نظريـة واحدة في العلوم

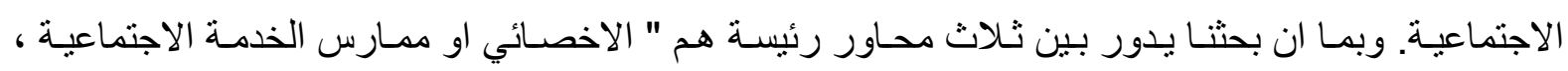

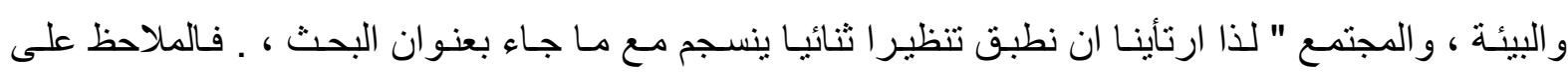

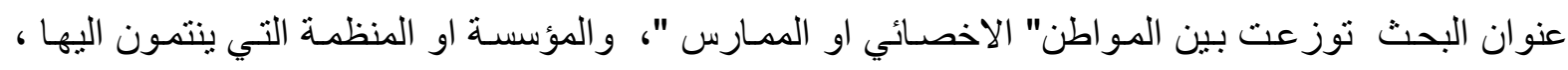
و البيئة ( المجتمع ) . فان هذه المحاور الثناثة مرتبطة ارتباطا كبير بمفهوم الممارس المهني للخدمـة الاجتماعية و البيئة ، ( فسوف تعني نظرية الدور للممارس المهني ودور في الوعي البيئي بالتقليل من التلوث و المحافظة

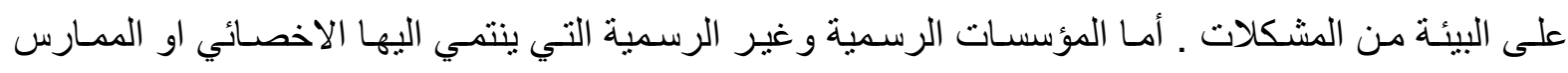

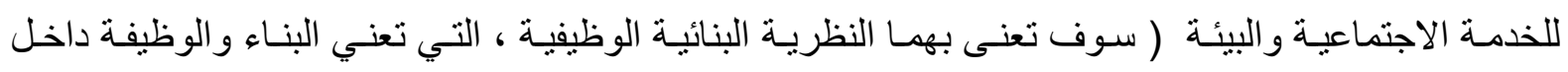

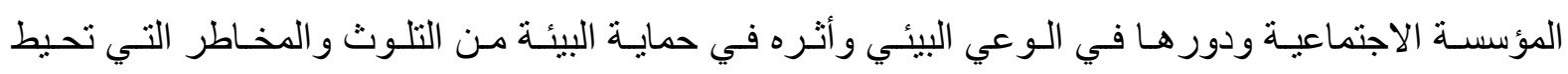

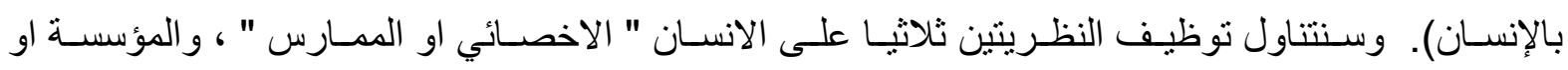

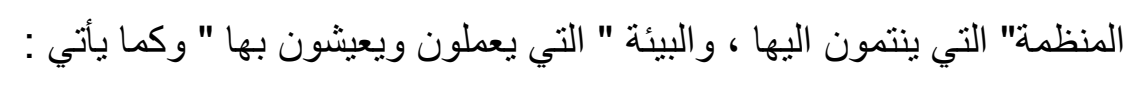
اولا : نظرية الدور. إن نظرية الدور في الحقيقة هي صورة من صور التفاعلية الرمزيـة، والتي يمكن عدّها

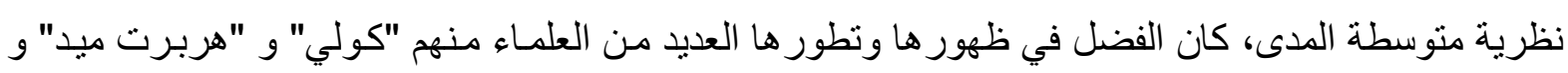
"جورج هربت بلومر" و "ترانر". ولعلنا نجد في در اسة "كولدمان" (عرض الذات على مسرح الحياة اليوميـة)،

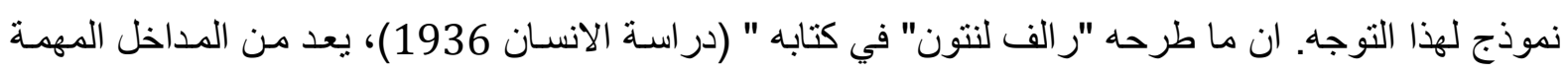

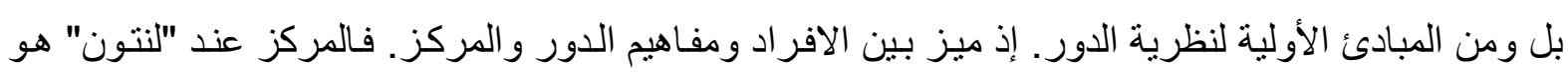
ببساطة (مجموعة الحقوق و الواجبات). أما الدور فهو (الجانب الدينامي للمركز) إذ إن المركز هو هو عبارة عن الدين

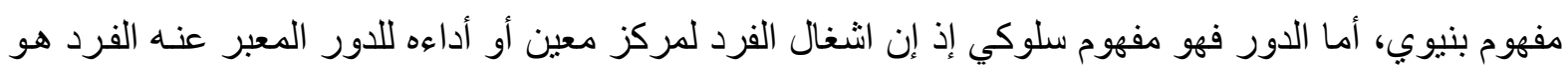
لا يجري من فراغ بـل يجري من تنظيم اجتمـاعي ( شيتا ، 1993 ، ص353). ان الفرد لا يشـل في المجتمع

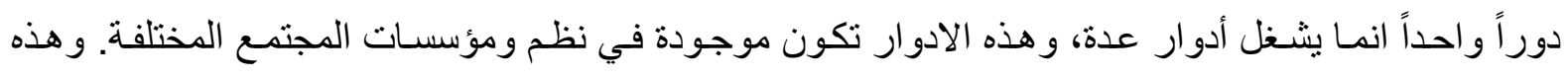

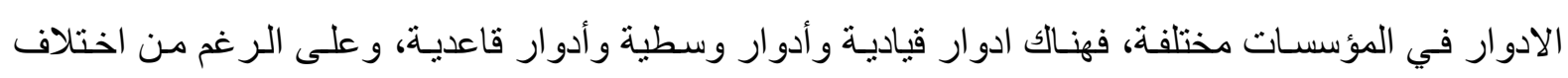
الادوار فأنها متكاملة، ويحدث الصر اع بين الادوار عندما تتطلب المؤسسـات من الفرد الواحد الذي يثـغل فيها ادو اراً مختلفة القيـام بمهامـه وواجباتـه في الوقت نفسـه ولا يستطيع ذلك. وأن السـوك الفاعل تحدده المعـايير

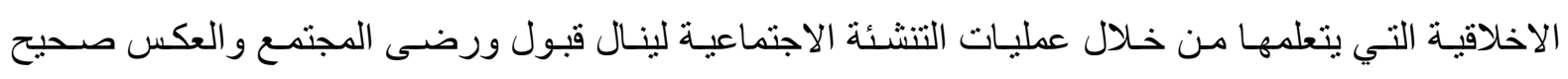

من هنا يمكن إذاً ان نستخلص من نظرية الدور والمفاهيم المتصلة به القضايا الآتية. 
يمارس الأفراد ( الاخصائيين او الممارسين ) أدوارهم الاجتماعية بالاستناد إلى التوقعات المتبادلة

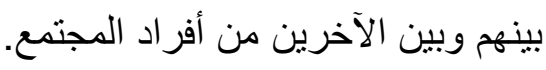

ان افر اد المجتمع ( الاخصـائيين او الممارسين ) وهم يمارسـون أدوارهم التوعويـة في المجتمـع

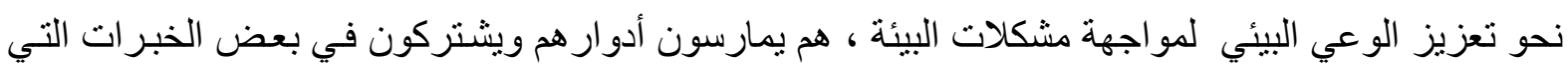
تتعلق بسلوكهم وبأدوار هم التوعوية للبيئة في مجتمعهم.

إن المعـايير الأخلاقيـة مـن عـادات وتقاليد وغيرهـا تؤدي دور هـا في بلوغ نسف الدور التوعوي

البيئي ومجابهة تحديات التلوث البيئي في المجتمع، وتتشكيل التوقعات المعياريـة لخدمة الوعي البيئي وسـلامة المجتمع من مخاطر ومشكلات البيئة.

إن كل مؤسسة اجتماعية هي عبارة عن وحدة اجتماعيـة تقام على نموذج بنـائي معين لكي تحقق أهدافها لصالح المجتمع، وذللك يتم من خلال أحداث الوعي البيئي ومجابهة المخاطر البيئية في المجتمع. تتـر ابط المر اكز مـع بعضـها في المؤسسـات الاجتماعيـة بأنو اعها المختلفة على أسـاس متغيرات الحجم، ودرجة التمايز، و العلاقات المتداخلة والمعقدة، فالمؤسسـة الاجتماعية لكي تأخذ دور هـا في نشر الوعي البيئي و التقليل من نسبة المشكلات الناتجة عن مخاطر البيئة يتم عن طريق أداء كل مؤسسـة او منظمـة تنظيميـة للأدوار المناطة بها لنشر الوعي البيئي ومقاومة مخاطر ومشكلات البيئة . كلمـا كانت أهداف التنظيم للمؤسسـات الاجتماعيـة واضـحة في المجتمع كلمـا كـان أداء ادوارهم .6 التو عوية للبيئة أكثر كفاءة ونجاح لتقليل نسبة مشكلات البيئة ومخاطر ها. ثانيـا : النظريـة البنائيسة الوظيفية "بارسونز". تنطوي فكرة ومضمون نظريـة النسق الاجتمـاعي على رؤيـة

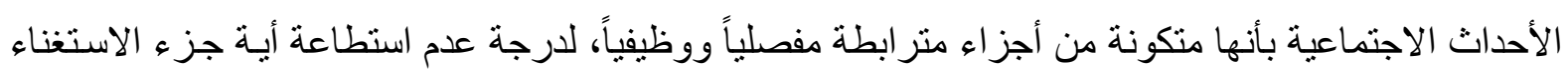
عن وجود الأجزاء الأخرى عند قيامهاه بحركته ووظيفته، على الرغم من أن حركة ووظيفة الكل مختلفة عن حركة ووظيفة أجزائه المكونة له، وذللك لأن كل جزء يقوم بحركة ووظيفة خاصـة بقدرتهـ واختصاصسه، التي

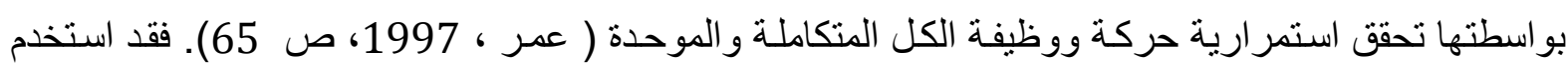
"نالكوت بارسونز" مصطلح " النسق الاجتماعي " كمر ادف لمصطلح " البناء الاجتمـاعي " ، ويتضمن النسق

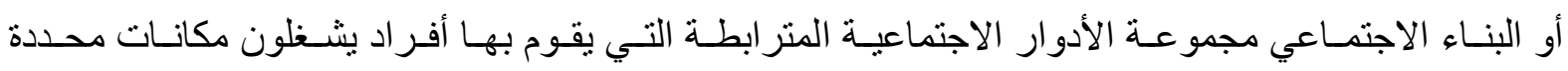
ويتفاعلون لتحقيق أهدافهم ضمن أطار ثقافي ، تحدد لهم ما هو شرعي، ومقبول ومميز. وطبق "بارسونز " فكرة النسـق في تحليل جميع مستويات الفعل الاجتمـاعي، سواء كان على مستوى الفرد، أو مستوى الجماعـة، أو مستوى المجتمع، و هذه المستويات تتضمن مجموعة من العناصر المترابطة والمساندة، يقوم كل عنصر بوظيفة

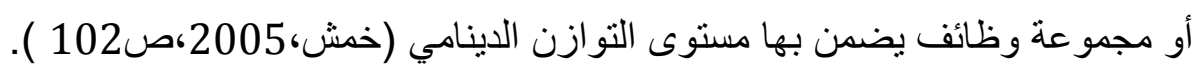
لا شك أن الوعي البيئي عمليـة مهمة تؤدي إلى حالة من الاستقرار والتوازن البنيوي، من خـلال مـا يوفره الوعي للوجود، و العيش الرغيد لأبناء المجتمع، عبر ما تقدمه المؤسسات الاجتماعية من رعاية وخدمات مؤسسية تتشر وتدعم الوعي البيئي، وتو اصله في ثقافة المجتمع عبر تتفيذ بر امجها المختلفة، ومخططاتها البيئية 
لمواجهته مخاطر ومشكلات البيئة من قبل أبناء المجتمع الواعيين. وبالعكس فأن عدم مواجهة مخاطر البيئة

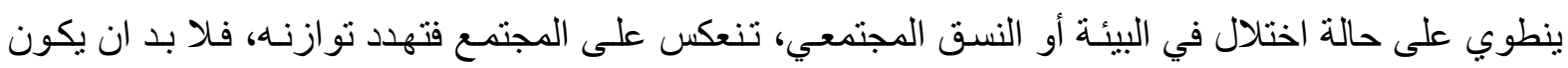

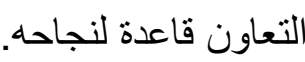

كان "بارسونز" قد أكد بدرجة كبيرة أهمية التتشئة الاجتماعية، وذلك بهدف استمرار نسق الفعل الثقافي، وهي أربع أنساق رئيسة هي:

\section{2. - 2. - النسق الاجتماعى. \\ 4. ت نسق النظام البايولوجي.}

1 - - النسق الثقافى.

3- نسق الثخصية.

وترتبت هذه الأنساق بحيث تعطى السيطرة للنسق الثقافي بينما نتبادل الأنساق الأخرى علاقات التنأثر

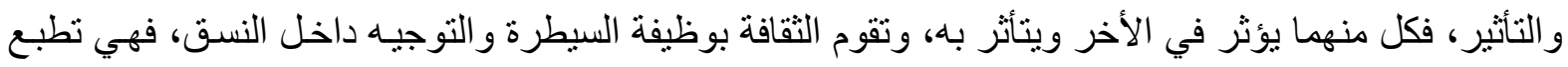
الانساق بطابع معني، وتوجه الأنساق بوجهه معنية. وذهب "بارسونز" إلى أن مفهوم النسق الاجتماعي يمثل

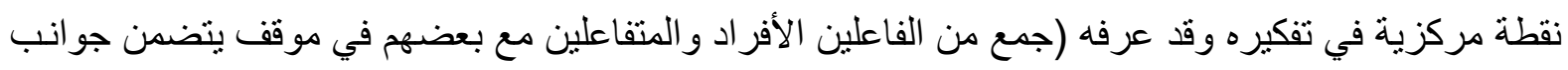

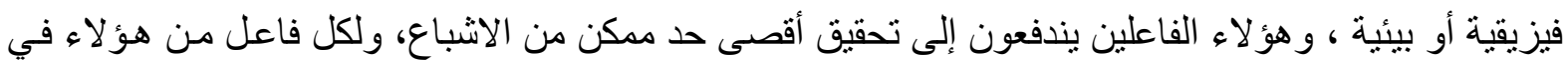

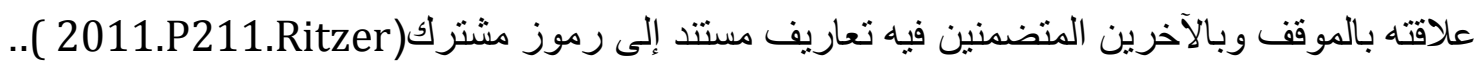
وقد بدأ " بارسونز" تحليله للنسق الاجتماعي من أصغر مكوناته و هو التفاعل الاجتماعي، والذي هو شبكة من العلاقات بين الأفراد و الجماعات أو حتى مجتمعات تتنظم بينها علاقات اجتماعية مستقرة، والتفاعل

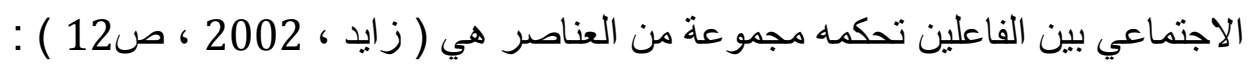
1- التوقعات المتبادلة بين الفاعلين والتي تجعل كلاً منهم يضع في اعتباره سلوك الآخرين. 2- القيم والمعايير التي يحكم التفاعل، وتحدد شكل التوقعات المتبادلة بين الفاعلين. 3- الجزاءات التي تظهر في أثنكال الثواب و العقاب تتحقق بذلك درجة من ضبط التفاعل. ومن المعلوم أن" بارسونز" جعل من النسق الثقافي مرجعية لتعريف المو اقق وما ينعلق به من علاقات

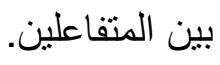

أما موضوع بحثنا "الخدمة الاجتماعية والممارسة والبيئة" لا يحدثان عشو ائياً، بل يخضعان لمرجعية

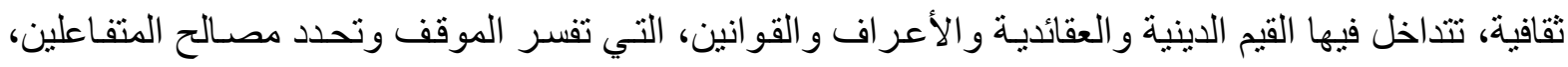

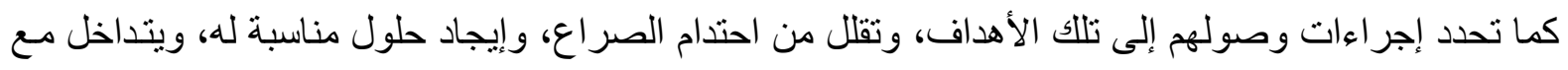
النظامين أو النسقين الاجتماعي والثقافي ونسق الثخصية ونسق العضوية السلوكية (البايولوجي). أن الوحدة الأساسية في نسق الثخصية هو الفرد الفاعل أو الثخص الإنساني، ويركز "بارسونز" هنا

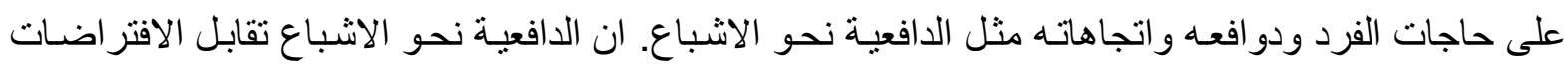

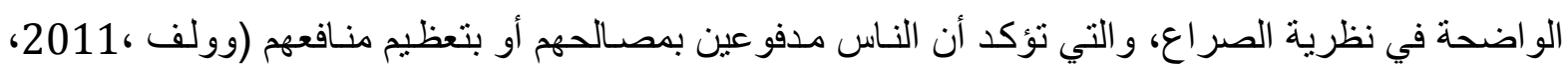


ص67) ـ و الممارسة المهنية للخدمة الاجتماعية و علاقتها بالبيئة ، نموذج للعلاقة الهادفة إلى تحقيق مصـالح أو غايات، أو اثباعات معينة للفاعلين في قضايا الوعي لحماية المجتمع من تحديات ومشكلات ومخاطر البيئة. النسق الر ابع عند" بارسونز" هو نسق العضوي البايولوجي والذي يشير إلى الإنسـان بمعنـاه البايولوجي

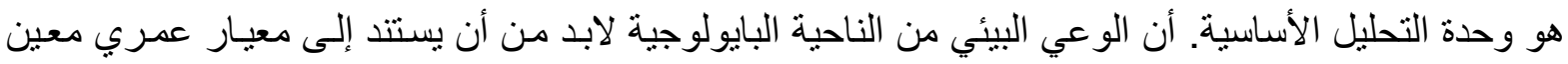
ليصبح الإنسان قادراً على تحمل مسؤولية الوعي ومعناه و أهميته، ومسؤوليته كمو اطن اتجاهـه، فضـلا عن ذلك اهتم " بارسونز" بالعلاقة بين المتفاعلين وبين البناءات الاجتماعية، وركز على عمليـة استدخال القيم من خـلال التنشئة الاجتماعيـة، إذ أن ذلك يشكل قاعدة لأداء الدور، كما يعبر عن القيم الأساسية في النسق الاجتمـاعي،

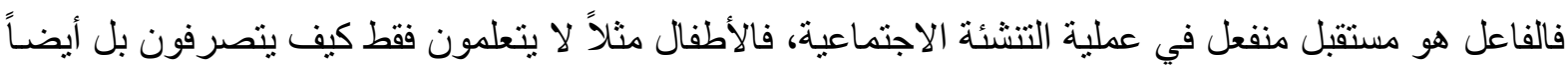
يتعلمون المعايير و القيم والأخلاق الاجتماعية ، ومن تللك القيم والمعايير والقواعد هي المتعلقة بالوعي البيئي في

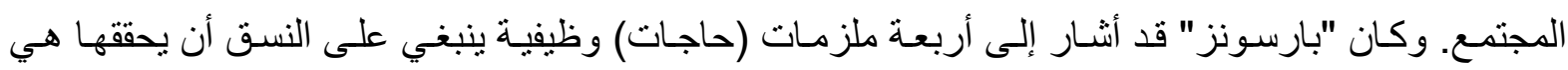

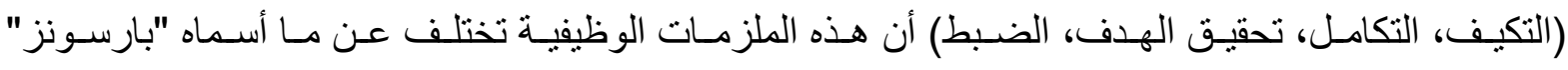
(بالمتطلبات الوظيفية)، رغم التثـابه الموجود بينهما، فالمنطلبـات الوظيفية تشير إلى تحقيق وانجاز الظروف بلاف الأساسية التي تساعد النظام الاجتماعي على البقاء و الاستمر ار، ومن هذه الظروف التنشئة الاجتماعية لتحمل

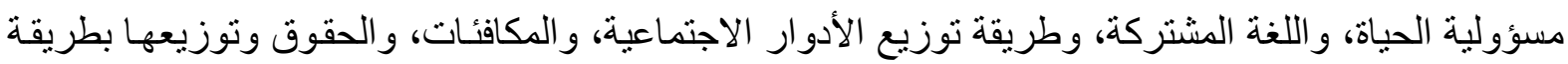

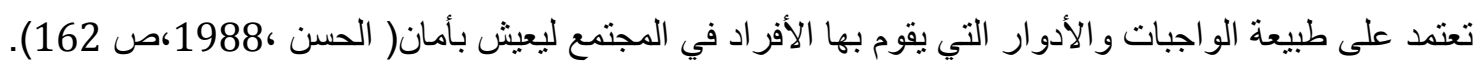
ويستعمل "بارسونز" نموذج الوظائف الأربع لتحليل أنساق المجتمع المتفرعة، إذ ميز بين أربع أنسـاق

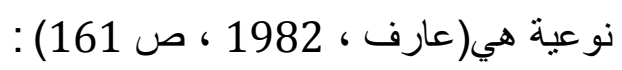

أــ النسق الاقتصادي: ويشمل مجمو عة أنشطة الإنتاج و التوزيع، ويحقق وظيفة التكيف. ب- النسق السياسي: ويشمل الأنشطة التي تتصل باتخاذ القرار وتعبئة الموارد ويحقق وظيفة تحقيق الهدف. ج- الروابط المجتمعية: هي مجموعة النظم التي تعمل على إقامة علاقات بين الأفراد و الجماعات، تجعلهم يحققون درجة عالية من التضامن مثل (القانون، الدين، النظم القضائية) وكل المؤسسـات التي تجمع الناس على التى

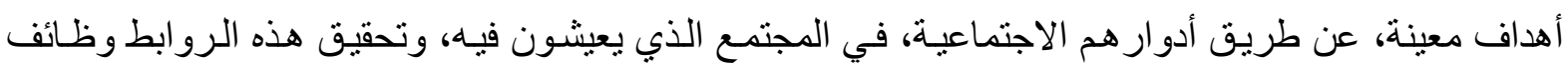
التكامل أي التتسيق اللازم لاستمرار المجتمع. د- التنشئة الاجتماعيـة : وتقوم بالمحافظة على نمو المجتمع ونقل ثقافته إلى الأفراد الذين يستدمجونها، وخلق الدافعية للسلوك الملزم، وتحقيق الضبط. ومن هنـا يتضـح ان الانسـاق الاجتماعيـة (النسـق الأسري، والنسق التربوي و التعليهي، النسق الديني، النسق الإعلامي، النسق الأمني) تؤدي وظائفها بتنشئة الأبناء على الوعي البيئي وغرس السلوك السوي الوطني مما يقلل من مخاطر التلوث البيئي. بذللك فأن النسف الاجتمـاعي، يتـالف من الجوانب البنائية المستقرة كالنظم الاجتماعية (الروابط المجتمعية)، ومن الجو انب الوظيفية الدينامية، كما تتمثل في العمليات الاجتماعية التي يقوم بها النسق لمواجهة مشكلاته وتحقيق توازنه وبقائه. 
في ضوء ما تقدم يمكن تحديد الأبعاد البنائية للنسق الاجتماعي هي :

أ- الأدوار التي ترتبط بالمر اكز و الأوضاع الاجتماعية. ج. القيم والمعايير الاجتماعية.

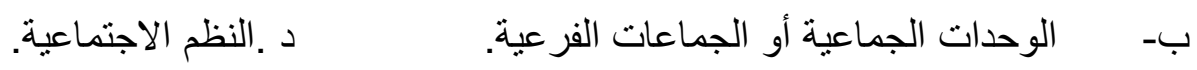

وفي ضوء ماتقدم برى "بارسنوز"، أن البناء الاجتماعي يتألف من النظم، وأن النظم تتألف من أدوار،

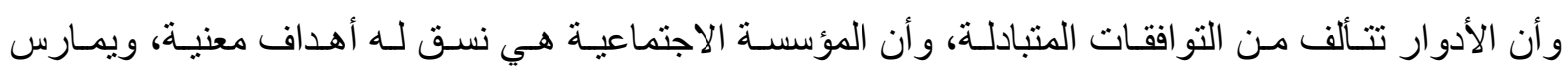
و اجباته ويحقق أهدافه من خلال الملزمـات الوظيفية الأربعة (التكيف ـ تحقيق الهدف ـ التكامل ـ الضبط). فالمؤسسة الاجتماعية تعنى وتوجه فعل الفاعل الاجتمـاعي في المجتمع ضمن حدود وضـوابط أخلاقيـة ودينية و عرقية، غايتها من ذلك توجيه دور الفاعل نحو أهداف انضباطية أخرى وجعله يتصرف فئ في أنماط مقبولة

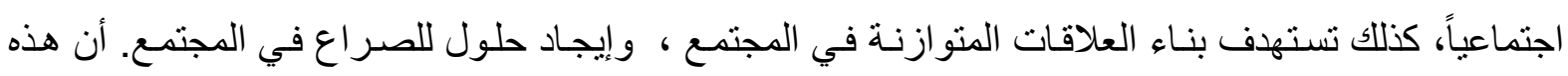

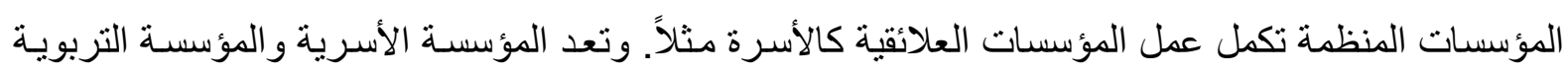
و التعليمية و المؤسسة الإعلامية و المؤسسة الدينية و المؤسسة الإعلامية ، مؤسسات متكاملة ومتوازنة، لكل منهما دور وظيفة ونظام، لتزويد أفر اد المجتمع بـالقيم و المعايير الاجتماعية كذلك القو انين و القو اعد و الأنظمـة، فكل منهما دور مكمل لبقية الأدوار، لتحقيق الهذف وهو الوعي البيئي في المجتمع.

الخاتمة :

ان البحث في مفـاهيم الممارسـة المهنيـة والبيئة، هو الجانب الـرئيس للمحافظـة على حيـاة الافر اد ،

و المسؤولية لا تقتصر على مؤسسـة معينـة أو مجموعـة من دون أخرى وعلى أفراد من دون آخرين بـل هي هي

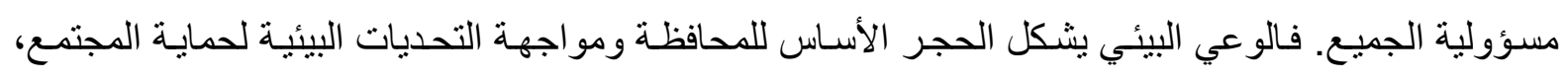
و هذا التحصين يأتي أو لا من المواطن ، لأن شعور المواطن بالوعي البيئي لمجتمعـه أنمـا يشكل سلوكاً وطنياً،

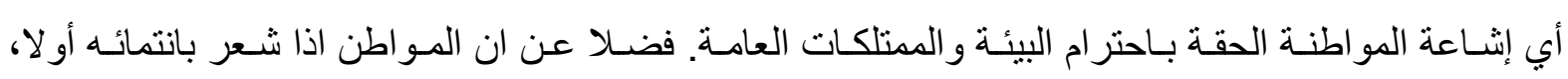
وللمؤسسات التي يعمل بها ثانيا، فأنه سيقوم بالمحافظة على البيئة من جميع النواحي.

فالحفاظ على البيئة يشكل إدر الك الفرد لنفسه و أدر اكه للظروف المحيطة به ، و الثعور بالدفاع عن البيئة

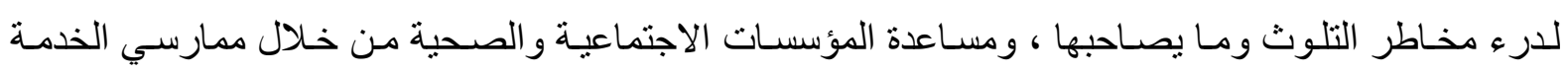

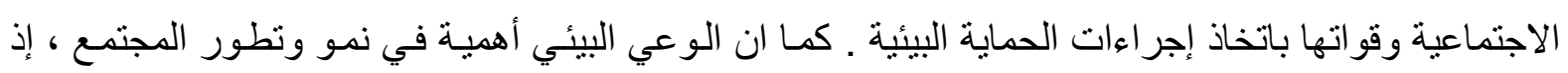
يساعد على النمو الاقتصادي ، أي لله علاقة بالتنمية . كذللك بناء الإنسان على أسـاس معرفة الحقوق و الواجبات الملقاة على عاتقه.

فدر اسة الخدمة الاجتماعيـة وعلاقتها بالبيئة يعد من البحوث الجديدة في علم الاجتمـاع بصورة عامـة و الخدمة الاجتماعية بصورة خاصة . مما دفع الباحثان البحث في المفاهيم الاساسية لتبيان العلاقة بين المفاهيم

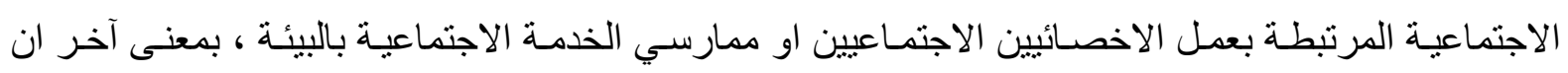

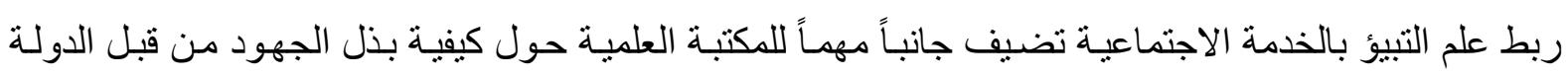
و المؤسسات الاجتماعية الأخرى لتحقيق بيئة صحية تحافظ على الإنسـان وصحته ، وكذلك محافظة الانسـان 
على البيئة ، مع ابراز دور بعض المؤسسـات في ترسيخ الوعي البيئي بين شريحة واسعة من أبناء المجتمع

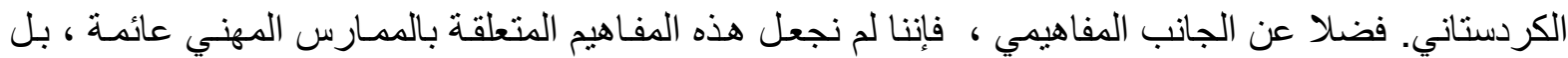
اننا وضعنا اتجاهات فكرية تنظيريـة مبنية على اطر و اسس علميـة ، لاسيما ان المو اطن و الاخصـائي بتمثلان

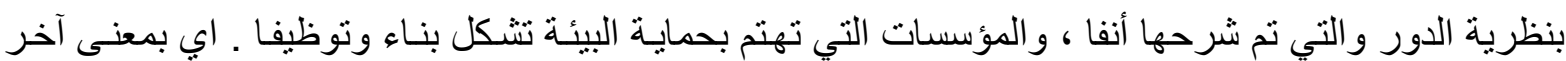
ان البنائية الوظيفية تقوم بمحاولة بيان أوجه القصور في هذه المؤسسـات في أثنـاء قيامها بالو اجب اتجاه حمايـة البيئة ، وتقديم مجموعة من التوصيات لصـانع القرار في هذه المؤسسـات وتحسين دور هـا حتى تستطيع القيام بهذه الوظيفة المهمة. فعن طريق الوعي البيئي يتم تعميق الثـعور والانتمـاء وغرس روح المشـاركة، وتحمل المسؤولية و المحافظة على البيئة ديمومتها.

هذا البحث يشكل بداية مفاهيمية تتظيرية توجه الباحثين و المختصين في العلوم البيئية والاجتماعية القيام بيحوث ودر اسـات تحليليـة وتطبيقية ، لا سيما المقارنـة بين مجتمعات لها بـاع في التنظيم البيئي للحمايـة من الكوارث البيئيـة ومخاطر هـا على الانسـان ومجتمعاتتـا الحديثـة العهد في التنظيم البيئسي ، لاسيما الاهتمسام بموضـوعة الـوعي البيئي للدى الافـر اد او المـواطنين لانهـ يشـلون الاسـاس في التنظيم البيئي ، ونعتقد ان

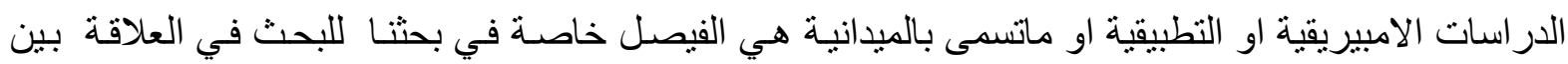
الممارسة المهنية و البيئة .

$$
\begin{aligned}
& \text { 1. }
\end{aligned}
$$

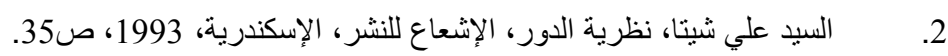

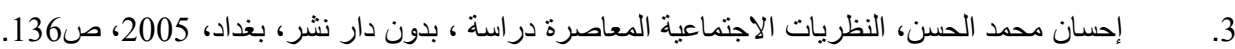

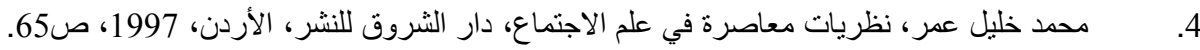

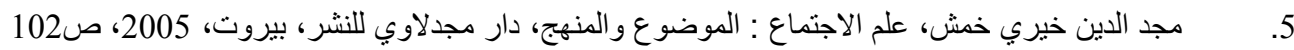

$$
\begin{aligned}
& \text { Ritzer, G, Sociological Ihory (New York : Me Crowttill, 2011), P.244. .6 } \\
& \text { 7. }
\end{aligned}
$$

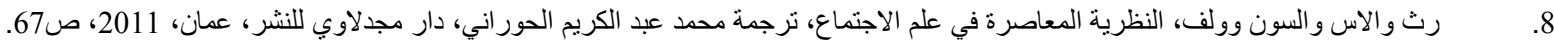

$$
\begin{aligned}
& 9 \text { 9. } \\
& \text { 10. محمد عارف، تالكوت بارسونز : رائد الوظيفية المعاصرة في علم الاجتماع، مكتبة الأنجلو المصرية، القاهرة، 1982، ص161. }
\end{aligned}
$$

